\title{
NILAI KARAKTER BANGSA DALAM SERAT BRATAYUDA SADURAN KAREL FREDRIK WINTER
}

Yoga Yolanda, Endang S ri Widayati, dan Furoidatul Husniah

Program Studi Pendidikan Bahasa Indonesia, Pascasarjana Universitas Negeri Malang

Jalan Semarang 5 Malang, Jawa Timur

Surel: yoga.y omail@gmail.com

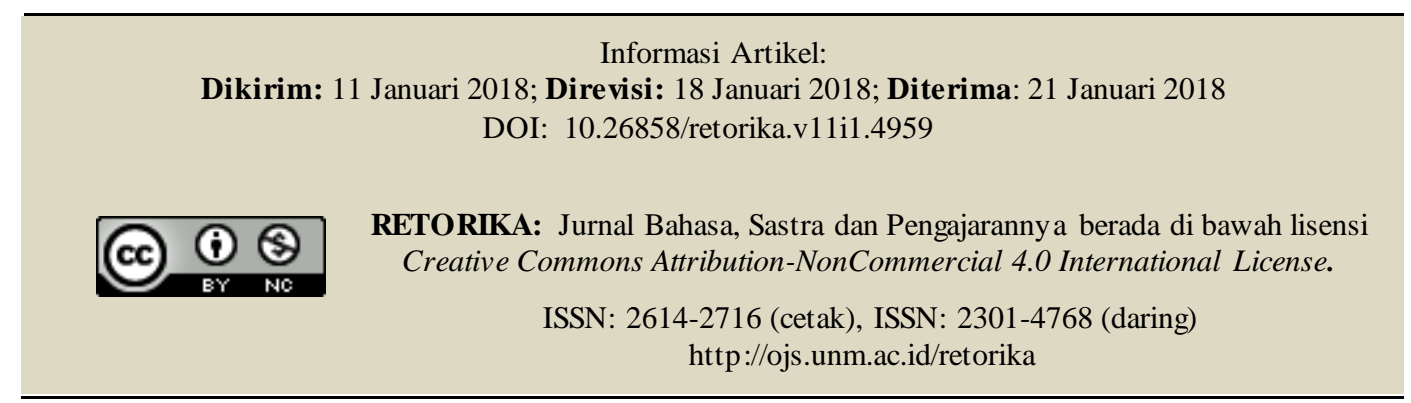

\begin{abstract}
Abstrak: Nation Character Values in Serat Bratayuda Adapted by Karel Fredrik Winter. This study aims to explain the nation character values in serat bratayuda obtained from the characters. This study used a qualitative approach with descriptive research type. Data collection techniques is documentation with data sources in the form of serat Bratayuda adapted by Karel Fredrik Winter. The data are words, sentences, and/or paragraphs in the serat bratayuda that indicate the appearance of characters. Through this research found seven nation cultural and characters values through dialogue and narration in Serat Bratayuda, i.e: (1) cinta tanah air, (2) cinta damai, (3) jujur, (4) pekerja keras, (5) kreatif, (6) tanggung jawab, dan (7) religius.
\end{abstract}

\begin{abstract}
Nilai Karakter Bangsa dalam Serat Bratayuda Saduran Karel Fredrik Winter. Penelitian ini bertujuan memaparkan nilai karakter bangsa dalam serat bratayuda yang didapatkan dari karakter tokoh-tokohnya. Penelitian ini menggunakan pendekatan kualitatif dengan jenis penelitian deskriptif. Teknik pengumpulan datanya berupa dokumentasi dengan sumber data berupa Serat Bratayuda saduran Karel Fredrik Winter. Data berupa kata, kalimat, dan/atau paragraf dalam serat bratayuda yang mengindikasikan munculnya karakter tokoh. Melalui penelitian ini ditemukan tujuh nilai budaya dan karakter bangsa melalui dialog maupun narasi dalam Serat Bratayuda, yaitu: (1) cinta tanah air, (2) cinta damai, (3) jujur, (4) pekerja keras, (5) kreatif, (6) tanggung jawab, dan (7) religius.
\end{abstract}

Kata kunci: nilai budaya, karakter bangsa, karakter tokoh, Serat Bratayuda 
Kisah perang Bratayuda adalah cerita yang penting. Serat Bratayuda merupakan gubahan dari Kakawin Bharatayuddha yang ditulis oleh Empu Sedah dan Empu Panuluh pada tahun 1079 Saka atas perintah Raja Jayabaya, pemimpin Kerajaan Kediri pada masa itu. Sebelum masuknya teknologi hiburan praktis, kisah perang Bratayuda yang sering dijadikan lakon dalam pementasan wayang telah menjadi primadona masyarakat Jawa. Namun demikian, cerita pewayangan yang memiliki fungsi hiburan dan kandungan nilai-nilai tinggi itu semakin ditinggalkan, bahkan tidak dikenali oleh sebagian masyarakat saat ini. Hal ini sejalan pendapat Achmad (2012:6) yang mengemukakan bahwa banyak kearifan lokal Jawa yang tergerus perkembangan zaman.

Perang Bratayuda sering menjadi lakon dalam pertunjukan wayang kulit. Dijadikannya wayang sebagai media pendidikan antara lain karena terdapat kekayaan nilai dalam lakon-lakon pewayangan. Dalam cerita Bratayuda, nilai-nilai tersebut dapat berasal dari karakter tokoh di dalamnya. Kasidi (2010:5) mengungkapkan bahwa pada era Orde Baru, wayang digunakan sebagai penerangan, pendidikan, dan hiburan. Bratayuda sebagai sebuah wayang bukan hanya hiburan, tetapi juga media pendidikan.

Nilai merupakan sesuatu yang penting bagi kehidupan manusia yang harus diketahui, disadari, dipahami, dan dilaksanakan karena keberadaannya menjadi pegangan hidup. Dalam karya sastra, nilai tidak muncul secara eksplisit, tetapi dapat diketahui melalui karakter tokoh yang ada di dalamnya. Kemendiknas (2010:3) menyatakan bahwa karakter adalah watak, tabiat, akhlak, atau kepribadian seseorang yang terbentuk dari hasil internalisasi berbagai kebajikan (virtues) yang diyakini dan digunakan sebagai landasan untuk cara pandang, berfikir, bersikap, dan bertindak.

Pentingnya karakter dalam diri manusia diungkapkan oleh Wiyani. Menurut Wiyani (2013: 23), seseorang akan menjadi tidak berguna atau bahkan membahayakan masyarakat jika karakternya rendah. Oleh karena itu, penting untuk dilakukan penggalian terhadap nilai-nilai pendidikan budaya dan karakter bangsa dalam karya sastra. Keberadaan karakter tokoh dalam karya sastra dapat dilihat dari dialog, sikap, cara berfikir, berperilaku, dan bertindak dari tokoh karya sastra tersebut.

Harimansyah (2012:3) mengatakan bahwa karya sastra senantiasa mengandung nilai. Sejalan dengan itu, Endaswara (2008:165) menyata- kan bahwa karya sastra diciptakan tidak lain sebagai alat menanamkan nilai-nilai moral dan budi pekerti. Dengan kata lain, nilai-nilai budaya dan karakter bangsa yang terdapat dalam karya sastra harus diimplementasikan dalam pembelajaran sastra, yang salah satunya dapat melalui materi pembelajaran sastra itu. Terkait hal tersebut, Muti'ah (2013:15) meyatakan bahwa pengembangan nilai karakter dalam pembelajaran bahasa dan sastra Indonesia memiliki tujuan agar: (1) siswa mampu menikmati dan memanfaatkan karya sastra untuk mengembangkan kepribadian, memperluas wawasan kehidupan, serta meningkatkan pengetahuan dan kemampuan berbahasa, dan (2) siswa menghargai dan membanggakan sastra Indonesia sebagai khazanah budaya dan intelektual manusia Indonesia.

Untuk dapat dipahami hingga dijadikan pegangan hidup, nilai harus dikembangkan dalam diri setiap manusia antara lain melalui pendidikan. Pengembangan nilai melalui pendidikan sudah dicanangkan di Indonesia. Nilai yang harus dimiliki peserta didik di Indonesia adalah nilainilai budaya dan karakter bangsa yang terdiri dari delapan belas (18) nilai, yakni religius, jujur, toleransi, disiplin, kerja keras, kreatif, mandiri, demokratis, rasa ingin tahu, semangat kebangsaan, cinta tanah air, menghargai prestasi, bersahabat/ komunikatif, cinta damai, gemar membaca, peduli lingkungan, peduli sosial, dan tanggung jawab (Kemendiknas, 2010:9). Sebagai karya sastra yang memiliki muatan nilai budaya yang tinggi, Serat Bratayuda diyakini mengandung nilainilai karakter bangsa yang relevan digunakan untuk mendidik generasi muda saat ini.

Nurgiyantoro dan Efendi (2013:392) mengungkapkan bahwa prioritas nilai yang harus diutamakan adalah nilai-nilai religius, jujur, cinta tanah air, peduli lingkungan, tanggung jawab, kreatif, gemar membaca, disiplin, dan mandiri. Serat Bratayuda yang memiliki keberagaman karakter tokoh dan kaya kandungan nilai merupakan karya sastra yang dapat dijadikan sebagai bahan pengembangan nilai budaya dan karakter bangsa. Menurut Suryaman (2010:125), untuk membangun karakter dan kepribadian peserta didik yang berakhlak mulia, berkarakter kuat, seperti kreatif, kompetitif, disiplin, menjunjung semangat kebangsaan, serta siap untuk menjadi manusia yang tangguh, diperlukan buku-buku sastra yang bahasanya indah, mengharukan pembacanya, membawakan nilai luhur kemanusiaan, serta mendorong untuk berbuat baik kepada sesama 
manusia. Aspek-aspek yang menjadi kriteria karya sastra yang baik ini dimiliki oleh Serat Bratayuda.

Berdasarkan penjelasan di atas, penelitian ini bertujuan untuk memaparkan nilai-nilai budaya dan karakter bangsa dalam Serat Bratayuda. Nilai budaya dan karakter bangsa tersebut didapatkan melalui dialog, sikap, cara berfikir, berperilaku, dan bertindak dari tokoh-tokoh yang terdapat dalam Serat Bratayuda.

\section{METODE}

Penelitian ini didesain dengan pendekatan kualitatif. Sumber data yang dikaji berupa dokumen Serat Bratayuda saduran Karel Fredrik Winter yang diterbitkan oleh Proyek Penerbitan Buku Sastra Indonesia dan Daerah, Departemen Pendidikan dan Kebudayaan pada tahun 1980. Menurut Ratna (2004:46) penelitian kualitatif dilakukan semata-mata untuk menguraikan fakta mengenai suatu gambaran dengan apa adannya atau alamiah dalam bentuk deskripsi, yaitu dengan kata-kata tertulis atau lisan dari subjek yang diteliti.

Data pada penelitian ini adalah dokumen tertulis berupa kata, kalimat, dan paragraf dalam Serat Bratayuda yang menunjukkan karakter tokoh. Data dibatasi pada karakter positif. Dalam naskah Serat Bratayuda terdapat naskah asli yang menggunakan bahasa Jawa dan naskah terjemahan berbahasa Indonesia. Untuk memudahkan penelitian, data yang digunakan adalah teks terjemahan berbahasa Indonesia karena peneliti tidak perlu menerjemahkan lagi.

Teknik pengumpulan data yang digunakan dalam penelitian ini adalah teknik dokumentasi. Teknik dokumentasi adalah teknik pencarian data mengenai hal-hal atau variabel yang berupa catatan, transkrip, buku, surat kabar, majalah, prasasti, notulen rapat, lengger, agenda, dan sebagainya Arikunto (2013:274). Pengumpulan data mengenai karakter tokoh dalam Serat Bratayuda dilakukan dengan urutan: (a) membaca secara berulang-ulang dengan teliti serat Bratayuda, (b) menyeleksi data, dan (c) melakukan kodefikasi pada setiap dimensi karakter tokoh. Instrumen pengumpulan data yang digunakan berupa tabel.

Teknik analisis data penelitian ini terdiri dari tiga alur kegiatan, seperti yang diungkapkan oleh Miles dan Huberman (1992:16), yaitu reduksi data, penyajian data, dan penarikan kesim- pulan. Dalam analisis data, instrumen yang digunakan adalah tabel analisis data.

\section{HASIL DAN PEMBAHASAN}

Pada bagian ini dipaparkan hasil penelitian dan dilanjutkan dengan pembahasan hasil penelitian. Karakter tokoh yang ditemukan dalam Serat Bratayuda adalah karakter cinta tanah air, cinta damai, jujur, kerja keras, kreatif, tanggung jawab, dan religius.

\section{Cinta Tanah Air}

Karakter cinta tanah air dalam serat Bratayuda ditunjukkan melalui usaha mempertahankan tanah air dengan cara berperang yang dilakukan tokoh Yudistira, Wrekodara, Arjuna, Nakula, Sadewa, dan Dewi Kunti. Hasil analisis dipaparkan sebagai berikut ini.

\section{Mempertahankan Tanah Air melalui Berperang}

Rasa cinta tanah air Yudistira, Wrekodara, Arjuna, Nakula, dan Sadewa dapat diketahui pada saat datangnya berita dari Raja Kresna tentang Suyudana yang tidak memberikan hak Pandawa atas negeri Astina. Berikut kutipannya:

Setelah Raja Kresna diam, para raja yang mendengarkan berita itu tertegun. Demikian pula Raja Darmaputra, Wrekodara, Arjuna, Nakula dan Sadewa. Raja Darmaputra beserta saudara-saudaranya lalu bertekad akan melaksanakan pesan ibunya, Dewi Kunti, yaitu akan merebut negeri Astina melalui peperangan. (hlm. 18)

Melalui sikap Pandawa, dapat dikatakan bahwa mencintai tanah air berarti harus rela mempertahankannya, termasuk berperang. Perang adalah keputusan terakhir setelah usaha meminta hak secara damai tidak dapat dilakukan. Selain melalui para Pandawa, karakter cinta tanah air juga didapatkan dari Dewi Kunti. Kecintaan Dewi Kunti terhadap tanah air dapat diketahui dari data berikut.

Ketika sudah bertemu dengan Dewi Kunti, Raja Kresna ditanyai sambil menangis, "Bagaimanakah ananda raja mengenai pekerjaanmu itu, apakah berhasil. Dan bagaimana akhirnya?" Raja Kresna menjawab, "Si Suyudana itu enggan rukun 
bersaudara sebab dia tidak rela jika separuh negeri Astina diminta, keinginannya harus direbut dalam peperangan". Dewi Kunti menjawab dengan terputus-putus, "Jika demikian kehendak si Suyudana, apalagi yang dipikirkan. Hanya adikmu si Yudistira itu saja kau nasihati agar jangan meninggalkan keutamaannya sebagai satriya yang mengurungkan niatnya untuk merebut negerinya yang menjadi kewajibannya. Orang yang mati dalam peperangan karena merebut negaranya, maka sudah pasti dia akan memperoleh sorga. Pesanku ananda raja, usahakanlah agar jadi berperang. (hlm. 16)

Saat Dewi Kunti bertanya tentang permintaan Raja Kresna atas separuh negeri Astina kepada Suyudana, Raja Kresna menjawab bahwa Raja Suyudana menolak dan menginginkan peperangan. Mendengar itu, Dewi Kunti berpesan kepada Raja Kresna agar menyampaikan kepada Yudistira bahwa mereka harus berperang untuk mempertahankan separuh negeri Astina yang sudah menjadi haknya, dan agar Yudistira sadar bahwa meninggal dalam peperangan akan mendapatkan surga. Melalui kutipan di atas, Dewi Kunti menunjukkan karakter cinta tanah airnya dengan memerintahkan Yudistira untuk tetap mempertahankan separuh negeri Astina walaupun dengan sebuah peperangan. Dewi Kunti yang memerintahkan anak-anaknya untuk menyetujui peperangan karena mempertahankan tanah air adalah sebuah bukti kecintaan terhadap tanah air tersebut.

\section{Cinta Damai}

Karakter cinta damai dalam serat Brata$y u d a$ ditunjukkan dengan tindakan mempererat tali persaudaraan yang ditunjukkan oleh beberapa tokoh, yakni Raja Kresna, Bisma, Druna, dan Dewi Gendari. Hasil analisis paparkan sebagai berikut ini.

\section{Mempererat Tali Persaudaraan}

Raja Kresna adalah tokoh yang diberi kuasa untuk menentukan jalan terbaik mengenai hak Pandawa atas negeri Astina. Karakter Raja Kresna dapat diketahui melalui berikut.

Raja Yudistira berkata pada Raja Kresna, "Kakanda raja junjungan hamba akan meminta milik hamba, yaitu negeri Astina yang separuh bagian tersebut. Agar supaya baiknya, maka kami serahkan perkara itu kepada paduka”. Raja Kresna menjawab, "Jika lalu demikian kehendak adinda yang memikirkan agar supaya langgeng dalam ikatan persaudaraan, maka hambalah yang akan menjalankan untuk meminta separuh bagian negeri Astina”. (hlm. 9)

Pada data di atas, Raja Kresna menunjukkan bahwa dirinya memiliki karakter cinta damai. Raja Kresna diberi hak dalam menentukan jalan keluar mengenai keinginan Raja Yudistira, namun Raja Kresna lebih memilih jalan yang membuat ikatan persaudaraan antara Pandawa dan Korawa tetap langgeng dengan tidak berperang. Selain dari tokoh Raja Kresna, karakter cinta damai berikutnya didapatkan dari tokoh Bisma, Druna, dan Dewi Gendari, contoh kutipannya sebagai berikut.

Yang sedang duduk tersebut lama berdiam diri, Raja Kresna lalu berkata, "Paman Destarata, tujuan hamba kemari adalah bermaksud akan merukunkan persaudaraan, jangan sampai terjadi perselisihan atau perkelahian. Siapakah yang tidak senang, semua perintah hamba senantiasa dituruti oleh paduka Raja Amarta beserta sanak saudaranya. Adapun pekerjaan yang hamba lakukan sekarang ini adalah atas kehendak adinda Raja Amarta yang memintas separuh bagian negeri Astina". Destarata menjawab, "Betul perkataan ananda raja itu dan alangkah baiknya!”. Keempat dewa tersebut menyambung percakapan, "Sangat baik sekali sarannya Raja Kresna itu dan sedikit juga tak ada salahnya dalam usahanya merukunkan persaudaraan". Bisma dan Druna menyetujui perkataannya keempat dewa tersebut, sedangkan Raja Suyudana hanya menunduk serta cemberut tidak berbicara sedikit pun juga. (hlm. 14)

Setelah Raja Kresna mengungkapkan maksud kedatangannya kepada Destarata, Destarata menjawab bahwa tujuan dari Raja Kresna itu adalah hal yang baik. Kemudian, Bisma dan Druna menyambung dengan mengiyakan perkataan empat dewa yang mendukung niat Raja Kresna untuk merukunkan Pandawa dan Korawa. Pada akhir kutipan, Dewi Gendari berbicara kepada anaknya, Suyudana, bahwa niat merukunkan persaudaraan adalah hal yang baik dan menyuruh Suyudana untuk menuruti keinginan Raja Kresna. Sikap dan perkataan setuju dari Bisma, Druna, 
dan Dewi Gendari atas keinginan Raja Kresna menunjukkan bahwa mereka adalah orang yang cinta damai. Mereka juga tidak menghendaki adanya peperangan antara bala Pandawa dan bala Krawa untuk memperebutkan negeri Astina.

\section{Jujur}

Jujur adalah perilaku yang didasarkan pada upaya menjadikan diri sebagai orang yang selalu dapat dipercaya dalam perkataan, tindakan, dan pekerjaan. Dalam serat Bratayuda, nilai kejujuran ditunjukkan dengan sikap menolak perintah untuk berbohong melalui tokoh Yudistira. Berikut paparan mengenai analisis tentang nilai tersebut.

\section{Menolak Perintah untuk Berbohong}

Yudistira adalah tokoh yang memiliki karakter jujur dalam serat Bratayuda. Sesaat setelah Wrekodara membunuh Raja Malawapati beserta gajahnya yang bernama Aswatama, Druna yang memiliki anak bernama Aswatama mengira bahwa yang meninggal adalah anaknya. Padahal, gajah yang bernama sama dengan anaknya. Mendengar hal itu, Raja Kresna menyuruh Yudistira untuk membenarkan bahwa yang meninggal adalah Aswatama, anak Druna, namun Yudistira tidak mau berdusta atau berbohong. Penolakan untuk berbohong adalah sikap yang menunjukkan karakter jujur dari Yudistira. Meskipun untuk membohongi lawan perangnya, dia tetap tidak mau. Berikut kutipannya.

Ketika Druna mendengarkan teriakan tadi, sangatlah terkejutnya serta menangis. Dia mengira bahwa putranya yang mati, sebab putranya bernama Aswatama. Kemudian dia mendekati akan menanyakan kepada Wrekodara dan Janaka, akan tetapi mereka telah diberitahu oleh Raja Kresna supaya berdusta, hanya Raja Yudistira yang tidak mau, demikian jawabnya kepada Raja Kresna, "Kakanda raja, hamba tidak mau berkata bohong. Selama hidup hamba, belum penah hamba berdusta. Keduanya, Pendeta Druna itu adalah guru hamba, jadi hamba semakin takut jika berdusta." (hlm. 45-46)

\section{Kerja Keras}

Kerja keras adalah perilaku yang menunjukkan upaya sungguh-sungguh dalam mengatasi berbagai hambatan dalam menjalankan tugas serta menyelesaikan tugas dengan sebaik-baiknya. Seseorang yang melakukan kerja keras dalam menjalankan pekerjaannya disebut sebagai pekerja keras. Dalam serat Bratayuda, nilai pekerja keras diperoleh melalui perilaku (1) pantang menyerah dan (2) semangat berjuang. Perilaku tersebut dimiliki oleh Wrekodara, Arya Seta, dan Abimanyu. Berikut ini adalah paparan hasil analisis beserta datanya.

\section{Pantang Menyerah}

Pantang menyerah dalam serat Bratayuda didapatkan dari tokoh Wrekodara dan Arya Seta. Perilaku Wrekodara yang menunjukkan bahwa dia adalah tokoh yang pantang menyerah dapat diamati dari kutipan berikut.

Raden Wrekodara lalu datang menolong Raden Sanga-sanga. Partipeya segera dipanah, kena dadanya lalu jatuh. Karena terasa sakit, maka sangatlah marahnya. Ketika dia mengetahui bahwa yang memanah adalah Raden Wrekodara, kemudian dia membalas memanah, mengenai bahu kirinya. Raden Wrekodara sangat terkejut, segera meletakkan Barga-Wastra serta maju dengan memegang gada. Raden Partipeya digadanya, hancur bersama-sama dengan keretanya. Disitulah kematian Partipeya oleh Raden Wrekodara. Anaknya Partipeya segera maju akan membalas kematian ayahnya. Raden Wrekodara diserangnya. Sangat ramai perangnya, dan akhirnya anak Partipeya mati digada oleh Raden Wrekodara. Kepala pasukan Adipati Ngawangga yang bernama Drestarata maju, tetapi juga mati digada oleh Raden Wrekodara, hancur sekeretanya. Raden Wrekodara sangatlah marahnya, siapa saja yang maju digada, sehingga banyak prajurit yang mati. kemudian adiknya Sangkuni yang bernama Anggajaksa dan Sarabasanta maju dengan membawa sepuluh ribu prajurit, mengeroyok Raden Wrekodara. Akan tetapi Raden Wrekodara tidak mengalami kesukaran dikeroyok dalam medan peperangan. Kemudian dia mulai melepaskan Barga-Wastra. (1980:42).

Wrekodara diserang secara terus menerus oleh lawan-lawannya mulai dari Partipeya, putra dari Partipeya, Drestarata, kedua adik Sangkuni, yakni Anggajaksa dan Sarabasanta beserta sepuluh ribu prajuritnya, namun Wrekodara tetap bekerja keras untuk melawan. Perjuangan dari 
Wrekodara memberikan gambaran bahwa dirinya memiliki karakter pekerja keras. Ketika melakukan hal yang berat, seperti Wrekodara yang berjuang melawan banyak musuh demi mempertahankan tanah air, dibutuhkan jiwa pantang menyerah agar mencapai hasil yang maksimal. Pantang menyerah dalam melawan musuh dalam perang adalah wujud dari cinta tanah air.

\section{Semangat Berjuang}

Semangat dalam berjuang merupakan karakter positif yang dimiliki oleh seorang yang kerja keras. Karakter pekerja keras dalam serat Bratayuda diperoleh dari Wrekodara, Arya Seta, dan Abimanyu. Karakter pekerja keras ditunjukkan Wrekodara adalah saat dia bekerja keras melawan musuh yang sangat banyak. Kerja keras Arya Seta adalah saat dia tidak mundur untuk melawan musuh yang sangat kuat. Karakter pekerja keras dari Abimanyu adalah saat dia tetap bersemangat dalam mencapai tujuan. Semangat berjuang dari Abimanyu dapat diidentifikasi dalam kutipan berikut.

\begin{abstract}
Abimanyu lalu menarik busurnya, akan tetapi patah. Sedangkan panahnya musuh tiada henti-hentinya menjatuhi dirinya, sehingga bagaikan hujan saja. Adapun perasaannya Abimanyu ketika dijatuhi panah-panah tersebut, seperti digaruk-garuk oleh orang perempuan. Abimanyu bergerak ke kanan dan ke kiri menangkapi panahpanah yang jatuh. Pernuatan Abimanyu ketika dikepung serta dijatuhi panah dapat digambarkan seperti berjumpa dengan seorang gadis. Tubuhnya telah hancur oleh luka-luka, namun dia tak berniat mundur dan keberaniannya tetap tidak berubah. (hlm. 32-33)
\end{abstract}

Semangat dalam berjuang ditunjukkan oleh Abimanyu. Sebelum meninggal, dia berusaha dengan keras menuju ke tempat Raja Suyudana yang menjadi incarannya sambil memanahi lawan yang menghadang. Dia berusaha terus walaupun banyak panah dari bala Korawa yang menancap memenuhi tubuhnya. Dia terus berusaha menuju Raja Suyudana sambil memanahi lawannya, namun panah lawan semakin memenuhi tubuhnya hingga dia benar-benar tidak dapat memanah lagi. Sampai busur panah lawan memenuhi tubuhnya pun dia tetap bersemangat untuk men- capai Raja Suyudana yang menjadi tujuan/sasaran utamanya.

\section{Kreatif}

Dalam serat Bratayuda, nilai kreatif ditunjukkan dengan berpikir dan melakukan sesuatu untuk menghasilkan strategi atau taktik dalam berperang. Karakter kreatif dalam serat Bratayuda adalah menuangkan kreativitas pada siasat perang yang diperoleh dari tokoh Bisma, Druna, Arya Seta, dan Abimanyu.

\section{Menuangkan Kreativitas pada Siasat Perang}

Dalam peperangan Bratayuda, baik bala Pandawa maupun Korawa selalu memilih panglima perang yang akan menjadi pengatur strategi perang. Tokoh yang dipilih menjadi pemimpin perang tentu adalah tokoh yang memiliki kemampuan lebih dalam merancang strategi atau siasat perang. Berikut adalah karakter kreatif Bisma yang didapat saat dia memperoleh kepercayaan dari bala Korawa agar bersedia menjadi panglima perang.

Siasat perangnya Bisma adalah bukit-lautan. Yang menjadi karangnya semua kereta dan gajah, yang menjadi ombaknya adalah para raja, sedangkan bala-bala kecil yang menjadi airnya. (hlm. 1980:22)

Mendapatkan kepercayaan menjadi panglima perang membuat Bisma menunjukkan kreativitasnya dalam membuat siasat perang sehingga dia membuat siasat bukit-lautan yang dia percaya mampu mengalahkan siasat perang lawan. Hal ini menggambarkan bahwa Bisma memiliki karakter kreatif dalam dirinya.

Sama halnya dengan Bisma. Pada suatu hari, Druna juga dipilih menjadi Panglima perang Korawa seperti dalam kutipan berikut.

Druna berkata kepada Raja Suyudana: "Apabila ananda raja menginginka agar Pandawa cepat-cepat musnah, hendaknya si Janaka dipisahkan dengan si Wrekodara selama satu hari. Jikalau kedua saudara itu tidak dipisahkan, pandawa tidak dapat rusak dan tidak dapat mati". Raja Gardapati melanjutkan, "Bila demikian hamba yang akan menantang si Janaka, agar jangan sampai berkumpul dengan barisan yang besar". Ketika Druna mengetahui bahwa Raden Dananjaya ke arah selatan dan Raden 
Wrekodara ke utara, kemudian dia mengganti siasat perangnya yang bernama Cakra. Dalam pikirannya siasat itu tidak dapat dirusak oleh musuh. (hlm. 30)

Druna menunjukkan kreativitasnya dengan membangun strategi perang. Yang pertama, memisahkan dua kekuatan besar pandawa, yakni Arjuna dan Wrekodara sehingga kekuatan pandawa akan berkurang. Yang kedua, saat keduanya terpisah, kreatifitas Druna kembali ditunjukkan dengan membangun siasat yang bernama Cakra. Dari peristiwa tersebut, dapat dikatakan bahwa Druna memiliki karakter kreatif.

Dalam peperangan, Bala Pandawa menentukan panglima perang yang memiliki karakter kreatif, salah satunya Arya Seta. Karakter kreatif Arya Seta diketahui melalui kutipan berikut.

\begin{abstract}
Siasat perangnya Arya Seta bernama senjata Wajra yang tajam. Yang berada di depan adalah Wrekodara, Raden Dananjaya Seta Srikandi dan semua balanya. Setyaki dan Drusta Jumena sebalanya berada di sebelah kirinya, akan tetapi agak ke belakang dekat dengan tempat Senapati Arya Seta. Raja Darmaputra dan Dwarawati berada di tengah-tengah, bergabun dengan para raja dan para adipati. (hlm. 22)
\end{abstract}

Kreativitas Arya Seta dapat diketahui pada saat dia mendapat kepercayaan dari bala Pandawa untuk memimpin peperangan. Dia membuat siasat perang yang dinamakan senjata Wajra yang tajam. Ketika mendapat kepercayaan, Arya Seta berupaya untuk membuat siasat perang yang baik digunakan untuk melawan Korawa. Peristiwa tersebut menunjukkan bahwa Seta merupakan orang yang berkarakter kreatif.

Menuangkan kreativitas untuk membuat siasat perang adalah tindakan yang mencerminkan karakter kreatif dari seseorang. Memiliki karakter kreatif akan membuat orang lain mempercayakan hal-hal yang membutuhkan kreativitas kepada Bisma, Druna, Arya Seta, dan Abimanyu. Dengan kreativitasnya, mereka menciptakan cara-cara baru untuk memecahkan masalah sehingga karakter kreatif adalah karakter positif yang harus dimiliki oleh setiap orang.

\section{Tanggung Jawab}

Dalam serat Bratayuda, nilai tanggung jawab ditunjukkan melalui sikap (1) memprioritas- kan pekerjaan dan perilaku (2) tanggung jawab sebagai orang tua. Nilai tersebut diketahui melalui tokoh Raja Kresna dan Dewi Gendari.

\section{Memprioritaskan Pekerjaan}

Karakter tanggung jawab dari Raja Kresna berkaitan dengan kewajibannya melaksanakan amanat yang sudah dipercayakan kepadanya oleh Yudistira. Berikut kutipannya.

Raja Kresna menjawab, "Adinda raja, terima kasih sekali. Jamuan makan nanti belakangan saja, apabila pekerjaan ini telah selesai!" Raja Suyudana berkata lagi, "Janganlah paduka menampik makan hamba!" Raja Kresna menjawab, "Mudah adinda raja, nanti belakangan saja!” Raja Kresna senang hatinya melihat para raja semua yang berada di dalam kerajaan atau para sesepuh yang menghadap. Kemudian, dia meminta diri kepada Raja Suyudana akan ke tempat pesanggrahannya dahulu. Raja Suyudana berkata, "Terserah kehendak kakanda raja, raja yang bijaksana di dunia ini!" Raja Kresna berkata, "Mudah-mudahan adinda raja menjumpai kebahagiaan dan semoga terlaksana lah pekerjaan yang hamba jalankan, yang kelak selamat akhirnya". (hlm. 12)

Saat Raja Kresna sampai di negeri Astina, ia mendapat jamuan dari Raja Suyudana. Akan tetapi, Raja Kresna memilih untuk menerima jamuan setelah beristirahat dan setelah pekerjaan yang dia laksanakan telah selesai, yakni meminta separuh negeri Astina yang menjadi hak Raja Yudistira. Sikap Raja Kresna saat menolak jamuan dengan mengatakan "Nanti belakangan saja, apabila pekerjaan ini selesai" adalah sikap yang mengutamakan tanggung jawab terhadap amanat yang diterimanya dari pada hal lain. Dalam hal ini, Raja kresna menunjukkan karakter tanggung jawab.

\section{Tanggung Jawab sebagai Orang Tua}

Karakter tanggung jawab dapat dimiliki oleh siapapun, termasuk dari seorang ibu terhadap anaknya. Tanggung jawab ibu terhadap anak antara lain mengingatkan anak agar tidak berperilaku tidak terpuji kepada orang lain, seperti yang dilakukan oleh Dewi Gendari. Karakter tanggung jawab Dewi Gendari sebagai orang tua dapat diketahui melalui data berikut. 
Raja Suyudana kemudian mengundurkan diri dari tempat pertemuan, yang mengiringinya adalah Sangkuni dan Drusasana. Dia lalu memerintahkan agar menyiapkan senjata-senjata. Demikianlah Korawa yang berjumlah seratus dan semua prajuritnya sudah bersiap-siap, demikian juga kuda, kereta, gajah telah lengkap semuanya. Yang memimpin adalah Arya Sindureja, dia ini yang dipercaya mengatasi kesukaran. Di sebelah utara, selatan, timur dan barat telah penuh sesak oleh barisan. Ketika itu Dewi Gendari mohon Desarata, agar berkata kepada Suyudana yaitu jangan sampai mempunyai hati pemarah dan keras kepala, juga mengingatkannya akan perbuatannya yang tidak baik ketika dia meninggalkan tamutamu. (hlm. 15)

Pada data tersebut, Dewi Gendari berpesan kepada Destarata agar berkata kepada anaknya, Suyudana, yang pergi meninggalkan diskusi tentang permintaan Raja Kresna atas hak Pandawa, yakni separuh negeri Astina agar tidak menjadi orang yang pemarah dan keras kepala. Melalui peristiwa tersebut, Dewi Gendari menunjukkan tanggung jawabnya kepada anaknya, Suyudana. Rasa tanggung jawab terhadap anaknya itu terlihat dari perilakunya yang gelisah saat Suyudana marah dan meninggalkan para tamu, kemudian berpesan kepada Destarata agar memberitahu Suyudana untuk tidak marah dan meninggalkan tamu. Yang dilakukan Dewi Gendari adalah hal yang harus dilakukan oleh seorang ibu terhadap anaknya sehingga dapat dikatakan bahwa melalui tokoh Dewi Gendari ditunjukkan karakter tanggung jawab.

\section{Religius}

Sikap, perilaku, atau tindakan yang termasuk ke dalam karakter religius dibagi ke dalam tiga bentuk, yakni pengakuan keberadaan Tuhan, pengakukan kekuasaan Tuhan, dan ketaatan kepada Tuhan. Karakter religius dalam Serat Bratayuda, yakni (1) selalu berdoa pada Tuhan, (2) tindakan spontan tentang keimanan pada Tuhan, (3) taat kepada Tuhan, (4) taat dan percaya pada kekuasaan Tuhan, dan (5) berdoa sebelum berperang. Karakter tersebut ditunjukkan melalui tokoh Raja Kresna, Suyudana, Bisma, dan Dewi Kunti. Paparan hasil analisisnya adalah sebagai berikut ini.

\section{Selalu Berdoa pada Dewa}

Karakter religius ditunjukkan tokoh Kresna yang ditunjukkan dengan sikap berdoa kepada dewa. Berikut adalah data tentang karakter religius dari tokoh Raja Kresna.

Raja Kresna berkata kepada Raden Dananjaya, "Hai adinda, bagaimanakah sekarang? Korawa sudah mengetahui sumpahmu yang akan membunuh Sindureja, maka sudah pasti si Sindureja dilindungi serta tidak diperkenankan keluar ke medan peperangan, agar supaya janjumu itu terlaksana!". Dananjaya berkata, "Terserah paduka sajalah!”. Raja Kresna berkata lagi, "Adapun syaratnya adinda, agar supaya tercapai cita-citamu itu, hendaknya engkau memuja saja supaya kelak dapat mengetahui kehendaknya dewa yang gaib itu". Dananjaya berkata lagi, "Hamba akan menjalankan petunjuk paduka". (hlm. 35).

Pada data di atas, Raja Kresna memerintahkan Arjuna untuk memohon kepada dewa. Perintah Raja Kresna terhadap Arjuna agar berdoa kepada dewa adalah tindakan yang menunjukkan karakter Religius. Raja Kresna berharap Arjuna menjadi orang yang percaya akan kekuasaan dewa atas semua yang terjadi dalam hidup. Dari dua data di atas dapat dikatakan bahwa Raja Kresna adalah tokoh yang memiliki karakter religius. Memberikan saran kepada seseorang untuk taat dan selalu berdoa kepada Tuhan merupakan tindakan yang menunjukkan karakter religius.

\section{Tindakan Spontan tentang Keimanan pada Dewa}

Data tentang tindakan spontan Suyudana dapat diidentifikasi pada awal cerita. Berikut kutipannya.

Raja Kresna menengadah, lantas datanglah empat dewa yaitu bernama Kaneka-putra, Janaka, Rama Parasu dan Kanwa. Bisma dan Druna mengatakan kepada Raja Suyudana bahwa ada dewa datang. Suyudana lalu menyembah dan serta menyilahkan ke empat dewa itu duduk. Mereka kemudian duduk bergabung dengan para sesepuh. Adapun para raja duduk bersatu dengan sesama raja, sedangkan para satria dengan satria. (hlm. 14). 
Mengetahui bahwa Raja Kresna datang bersama dewa, Raja Suyudana langsung menyembah keempat dewa tersebut. Melalui data di atas, Raja Suyudana menunjukkan perilaku religiusnya dengan secara spontan menyembah dewa saat para dewa datang ke istananya. Tindakan pengakuan terhadap keberadaan Tuhan itu ditunjukkan Suyudana dengan secara spontan menyembah para dewa.

Tindakan spontan yang berkaitan dengan keimanan seseorang kepada Tuhan sering dijumpai dalam kehidupan sehari-hari, misalnya seseorang yang beragama islam spontan mengucapkan innalillahi wa inna 'illaihiraji'un saat mendengar berita kematian. Spontan terhadap hal yang berkaitan dengan ketuhanan adalah perilaku yang selalu dilakukan manusia sebagai makhluk yang beriman terhadap keberadaan Tuhan.

\section{Taat kepada Perintah Dewa}

Perang Bratayuda adalah perang yang dikehendaki para dewa. Oleh karena itu, mereka yang taat kepadaNya tidak akan meninggalkan perang karena takut dengan lawan. Ketaatan itu ditunjukkan oleh Bisma. Berikut kutipannya.

\footnotetext{
Bisma merasa gentar melihat Seta, kemudian dia mundur dari peperangan dan tidak jadi menyerangnya. Ketika itu terdengarlah suara dewa dari angkasa, "Hai Bisma, apakah sebabnya engkau mundur dari medan laga. Ketahuilah engkau, bahwa matinya putra Wirata itu adalah olehmu!". Setelah Bisma mendengar suaranya dewa kemudian dia kembali, serta menarik panah api. (hlm. 24).
}

Setelah melihat tingkah laku Arya Seta yang marah dan menghajar banyak lawan, Bisma berniat untuk kabur karena takut, namun ketika mendapat peringatan dari dewa bahwa Seta marah karena Bisma yang membunuh putranya, Bisma langsung kembali untuk bertempur dengan Seta. Bisma menjalankan apa yang dikehendaki oleh penciptanya. Peristiwa tersebut menunjukkan bahwa Bisma adalah orang yang taat terhadap dewa.

\section{Taat dan Percaya pada Kekuasaan Dewa}

Sikap taat dan percaya pada kekuatan dewa ditunjukkan melalui nasihat Dewi Kunti. Nasihat Dewi Kunti tentang taat dan percaya kepada kekuasaan Tuhan dapat diidentifikasi melalui data berikut.

Dewi Kunti menjawab dengan terputusputus, "Jika demikian kehendak $\mathrm{Si}$ Suyudana, apalagi yang dipikirkan. Hanya adikmu Si Yudistira itu saja kau nasihati agar jangan meninggalkan keutamaannya sebagai satriya yang mengurungkan niatnya untuk merebut negerinya yang menjadi kewajibannya. Orang yang mati dalam peperangan karena merebut negaranya, maka sudah pasti dia akan memperoleh sorga. Pesanku ananda raja, usahakanlah agar jadi berperang. (hlm. 16)

Data di atas adalah tentang Raja Kresna yang menjawab bahwa Raja Suyudana menolaknya dan menginginkan peperangan. Mendengar itu, Dewi Kunti berpesan kepada Raja Kresna agar Yudistira, anaknya, mau berperang untuk mempertahankan separuh negeri Astina yang sudah menjadi kewajibannya dan agar Yudistira sadar bahwa meninggal dalam peperangan akan mendapatkan surga. Dewi kunti menunjukkan karakter religiusnya dengan mengatakan bahwa orang yang meninggal dalam peperangan akan mendapatkan balasan, yakni masuk surga. Hal itu adalah rasa keimanan terhadap Tuhan yang dimiliki Dewi Kunti. Selain melalui data di atas, karakter religius dari Dewi Kunti juga didapati dalam kutipan berikut.

\begin{abstract}
Adipati Ngawangga berkata, "Hamba diminta agar pergi dari negeri sini dan jika jadi perang, hamba dinasihati untuk membantu Pandawa". Dewi Kunti menjawab, "Nasihat yang demikian itu sangat baik sekali, sebaiknya kau turuti. Jadi, nanti engkau berkumpul jadi satu dengan saudarasaudaramu sebab di dalam perang Bratayuda itulah tempatnya kematian yang mulia. Hidup atau mati sebaiknya kau berkumpul dengan saudaramu sendiri”. (hlm. 17)
\end{abstract}

Adipati Ngawangga atau Karna berkata kepada ibunya, Dewi Kunti, bahwa ia diminta oleh Raja Kresna untuk membantu Pandawa dalam perang Bratayuda. Dewi Kunti membenarkan nasihat itu. Ia setuju dengan Raja Kresna dan berkata bahwa Karna dapat berkumpul dengan saudara-saudaranya saat perang dan karena perang Bratayuda dipercaya sebagai tempatnya kematian yang mulia, maka Karna diminta untuk berkumpul dengan Pandawa baik dalam kondisi hidup 
ataupun meninggal dalam perang nanti. Dalam kutipan data di atas, Dewi kunti kembali menunjukkan bahwa dia berkarakter religius, yakni percaya dengan kekuasaan Tuhan dengan menasihati anaknya, Karna. Nasihat Dewi Kunti adalah nasihat dari orang tua kepada anaknya. Menasihati anak untuk taat dan percaya kepada kuasa Tuhan merupakan tindakan orang tua yang berkarakter religius.

\section{Berdoa Sebelum Berperang}

Religiusitas Gatotkaca adalah tindakannya yang memperlihatkan pengakuan terhadap kekuasaan Tuhan. Berikut adalah kutipannya.

\section{Semoga hamba mendapat restu jika sampai pada kematian. Serta mendapat restu dalam membunuh musuh. Jikalau hamba mati dalam medan peperangan, mudah-mudahan paduka memberikan surga bagi hamba. (hlm. 44)}

Saat mendapat mandat melawan Karna dalam perang Bratayuda, Gatotkaca berharap apabila meninggal dalam perang itu dia memohon agar diberi balasan surga. Gatotkaca memasrahkan hidupnya kepada Batara Wisnu, dia menjalankan perintahnya untuk berperang melawan Karna yang merupakan satriya yang sulit dikalahkan. Dia pun memohon restu jika nantinya banyak membunuh lawan. Sikap dari Gatotkaca memberikan penjelasan bahwa dia berkarakter religius. Melalui tindakan Gatotkaca dapat diambil pelajaran bahwa berdoa kepada Tuhan sebelum melakukan kegiatan atau perkara apapun merupakan tindakan yang menunjukkan pengakuan terhadap kuasa Tuhan karena dengan berdoa seseorang percaya bahwa apapun yang akan terjadi merupakan kehendak Tuhan.

\section{Pembahasan}

Melalui analisis data yang dipaparkan di atas, dari 18 nilai budaya dan karakter bangsa yang dirumuskan oleh Kemendikbud (2010), tujuh di antaranya didapatkan dalam Serat Bratayuda, yaitu (1) cinta tanah air: ditunjukkan melalui sikap siap berperang untuk mempertahankan tanah air yang diperoleh dari beberapa tokoh, yakni Yudistira, Wrekodara, Arjuna, Nakula, Sadewa, dan Dewi Kunti, (2) cinta damai yang tampak dari tindakan mempererat tali persauda- raan yang diperoleh dari tokoh Raja Kresna, Bisma, Druna, dan Dewi Gendari, (3) jujur: tampak dari tindakan menolak perintah untuk berbohong yang ditunjukkan melalui tokoh Yudistira, (4) kerja keras: ditunjukkan melalui sikap pantang menyerah dan semangat untuk terus berjuang yang dimiliki oleh Wrekodara, Arya Seta, dan Abimanyu, (5) kreatif: ditunjukkan melalui tindakan menuangkan kreativitas dalam membangun siasat perang yang diperoleh dari karakter tokoh Bisma, Druna, Arya Seta, dan Abimanyu, (6) tanggung jawab: tampak dari perilaku memprioritaskan tanggung jawab atas pekerjaan yang sedang dikerjakan daripada melakukan hal lain, dan tanggung jawab orang tua dengan mengingatkan anaknya yang berperilaku tidak terpuji kepada orang lain. Nilai ini tampak dari tokoh Raja Kresna dan Dewi Gendari, dan (7) karakter religius tampak melalui tindakan pengakuan keberadaan Tuhan, pengakuan kekuasaan Tuhan, dan ketaatan kepada Tuhan. Pengakuan keberadaan Tuhan ditunjukkan melalui perilaku spontan menyembah dewa. Pengakuan kekuasaan Tuhan ditunjukkan melalui perintah untuk berdoa kepada Dewa, nasihat untuk percaya dengan kuasa dewa, dan melakukan doa sebelum berperang. Ketaatan kepada Tuhan berupa sikap yang tidak ingin menghindari perang karena merupakan kehendak Dewa. Nilai religius tampak dari tokoh Raja Kresna, Suyudana, Bisma, dan Dewi Kunti.

Dari hasil yang dipaparkan di atas ditunjukkan bahwa nilai-nilai luhur yang sesuai dengan nilai budaya dan karakter bangsa berasaldari karakter positif tokoh-tokoh di dalamnya. Karakter positif tersebut tidak hanya didapatkan dari tokoh-tokoh protagonis (Pandawa), tetapi juga dari tokoh-tokoh antagonis (Korawa). Selain itu, kandungan nilai-nilai luhur di dalam Serat bratayuda menunjukkan bahwa karya tersebut relevan dengan ciri-ciri karya sastra yang diprioritaskan untuk diutamakan dalam pembelajaran. Oleh karena itu, kisah dalam Serat Bratayuda sangat sesuai untuk dijadikan sebagai alternatif materi pembelajaran sastra untuk menumbuhkan karakter siswa. Melalui hasil penelitian ini, Serat Bratayuda dapat diadaptasi dalam kemasan cerita pendek, komik, atau bentuk penceritaan lain yang menonjolkan karakter-karakter positif dari tokoh di dalamnya sehingga nilai-nilai budaya dan karakter bangsa dapat terintegrasi dengan baik dan menarik bagi siswa.

Pengadaptasian dalam bentuk-bentuk tersebut didasarkan pada kebutuhan siswa, yakni re- 
levansinya dengan kompetensi yang akan dicapai. Dalam Kurikulum 2013, misalnya, prosa klasik seperti Serat Bratayuda tidak tercantum dalam kompetensi dasar sehingga adaptasi dalam bentuk penceritaan lain perlu untuk dilakukan. Selain itu, telah dibuktikan dalam penelitian Wicaksana (2012) bahwa pengadaptasian karya sastra dalam bentuk yang tidak panjang dan menarik dapat membuat siswa lebih sering melakukan telaah karya sastra, mudah menemukan nilainilai moral, serta mengimplementasikannya dalam kehidupan sehari-hari.

Dengan nilai-nilai di dalamnya, kisah perang Bratayuda yang pernah memiliki masa keemasan dalam masyarakat karena merupakan alat untuk menerangi, menghibur, dan mendidik masyarakat Jawa masih relevan apabila dijadikan bahan ajar untuk menanamkan karakter pada diri siswa. Hasil penelitian ini dapat dipertimbangkan pendidik untuk memanfaatkan karya-karya sastra klasik yang kaya akan nilai budaya dan karakter bangsa dalam proses pembelajaran.

\section{SIMPULAN}

Melalui penelitian disimpulkan bahwa dalam serat Bratayuda terdapat karakter tokoh yang relevan dengan nilai-nilai pendidikan budaya dan karakter bangsa, yaitu: (1) karakter cinta tanah air ditunjukkan melalui sikap siap berperang untuk mempertahankan tanah air; (2) karakter cinta damai tampak dari sikap dan tindakan yang bertujuan untuk mempererat tali persaudaraan; (3) karakter jujur tampak dari tindakan me-

\section{DAFTAR RUJUKAN}

Achmad, S. W. 2012. Wisdom van Java: Mendedah Nilai-Nilai Kearifan Jawa. Yogyakarta: iN AzNa Books.

Arikunto, S. 2013. Prosedur Penelitian: Suatu Pendekatan Praktik. Jakarta: Rineka Cipta.

Endaswara, S. 2008. Metodologi Penelitian Sastra. Yogyakarta. Media Pressindo.

Harimansyah, G. 2012. Mereposisi Pengajaran Bahasa dan Sastra: Sumbang Saran untuk Mengurai Problem Pengajaran Bahasa dan Sastra. Stilistika, 1(1): 1-19.

Kasidi. 2010. Inovasi dan Transformasi Wayang Kulit. Yogyakarta: Lembaga Studi Jawa.

Kemendiknas. 2010. Pengembengan Pendidikan Budaya dan Karakter Bangsa. Jakarta: Pusat Ke- nolak perintah untuk melakukan kebohongan; (4) karakter pekerja keras ditunjukkan melalui tindakan pantang menyerah dalam melawan musuh, serta sikap semangat dalam berjuang; (5) karakter kreatif ditunjukkan melalui tindakan menuangkan kreativitas dalam membangun siasat perang, (6) karakter tanggung jawab tampak dari perilaku memprioritaskan tanggung jawab atas pekerjaan yang sedang dikerjakan daripada melakukan hal lain dan tanggung jawab orang tua dengan mengingatkan anaknya yang berperilaku tidak terpuji kepada orang lain; dan (7) karakter religius tampak melalui tindakan pengakuan keberadaan $\mathrm{Tu}$ han, pengakuan kekuasaan Tuhan, dan ketaatan kepada Tuhan. Pengakuan keberadaan Tuhan berupa perilaku spontan menyembah dewa. Pengakuan kekuasaan Tuhan berupa perintah untuk berdoa kepada dewa, nasihat untuk percaya dengan kuasa dewa, dan melakukan doa sebelum berperang. Ketaatan kepada Tuhan berupa sikap yang tidak ingin menghindari perang karena merupakan kehendak dewa.

\section{UCAPAN TERIMA KASIH}

Ucapan terima kasih diberikan kepada Lembaga Pengelola Dana Pendidikan (LPDP) dan Pascasarjana Universitas Negeri Malang yang memberikan dukungan pelaksanaan penelitian serta penyempurnaan dan pemublikasian hasil penelitian ini. Ucapan terima kasih diberikan pula kepada mitra bestari (reviewers) yang telah memberikan saran, kritik, dan rekomendasi perbaikan artikel ini.

menterian Pendidikan Nasional Badan Penelitian dan Pengembangan Pusat Kurikulum.

Miles, M. B. dan Huberman, A. M. 1992. Analisis Data Kualitatif: Buku Sumber Tentang Metodemetode Baru. Jakarta: UI-Press.

Muti'ah, A. 2013. Pengembangan Karakter dalam Pembelajaran Bahasa dan Sastra Indonesia. Makalah. Disampaikan dalam Seminar Nasional Bahasa, Sastra, dan Pembelajarannya, Universitas Jember, 3 November 2013.

Nurgiyantoro, B. \& Efendi, A. 2013. Prioritas Penentuan Nilai Pendidikan Karakter dalam Pembelajaran Sastra Remaja. Cakrawala Pendidikan, 3(3): 382-393.

Ratna, N. K. 2004. Teori, Metode, dan Teknik Penelitian Sastra: Dari Strukturalisme hingga Pos- 
trukturalisme, Perspektif Wacana Naratif. Yogyakarta: Pustaka Pelajar.

Suryaman, M. 2010. Pendidikan Karakter melalui Pembelajaran Sastra. Cakrawala Pendidikan, 3(3): 112-126.

Wicaksana, M. F. 2012. Pendidikan Nilai-Nilai Moral melalui Pengajaran Sastra Berbentuk Komik
Multimedia Berbasis Flash dengan Mengadaptasikan Kearifan Budaya Lokal. Widyabastra Online, http: id.portalgaruda.org, diakses: 21 Januari 2018.

Wiyani. N. A. 2013. Konsep, Praktik, \& Strategi Membumikan Pendidikan Karakter di SD. Yogyakarta: Ar-Ruzz Media. 